\section{Safety and efficacy of PDpoetin for management of anemia in patients with end stage renal disease on mainte- nance hemodialysis: results from a phase IV clinical trial}

\author{
Abbas Norouzi Javidan, ${ }^{1}$ \\ Heshmatollah Shahbazian, ${ }^{2}$ \\ Amirhossein Emami, ${ }^{1}$ \\ Mir Saeed Yekaninejad, 3 \\ Hassan Emami-Razavi, ${ }^{1}$ \\ Masoumeh Farhadkhani, ${ }^{1}$ \\ Ahmad Ahmadzadeh, ${ }^{4}$ Fazel Gorjipour ${ }^{5}$ \\ 1Department of Physiology and \\ Pharmacology, Brain and Spinal Injury \\ Center, Imam Khomeini Hospital, Tehran \\ University of Medical Sciences; ${ }^{2}$ Division \\ of Nephrology and Transplantation, \\ Diabetic Research Center, Jondishapur \\ University of Medical Sciences, Ahvaz; \\ ${ }^{3}$ Department of Epidemiology, School of \\ Public Health, Tehran University of \\ Medical Sciences; ${ }^{4}$ Health Research \\ Institute, Research Centre of Thalassemia \\ and Hemoglobinopathies, Ahvaz \\ Jundishapur University of Medical \\ Sciences; ${ }^{5}$ Physiology Research Center, \\ Faculty of Medicine, Iran University of \\ Medical Sciences, Tehran, Iran
}

\section{Abstract}

Recombinant human erythropoietin (rHuEPO) is available for correcting anemia. PDpoetin, a new brand of rHuEPO, has been certified by Food and Drug Department of Ministry of Health and Medical Education of Iran for clinical use in patients with chronic kidney disease. We conducted this post-marketing survey to further evaluate the safety and efficacy of PDpoetin for management of anemia in patients on maintenance hemodialysis. Patients from 4 centers in Iran were enrolled for this multicenter, open-label, uncontrolled phase IV clinical trial. Changes in blood chemistry, hemoglobin and hematocrit levels, renal function, and other characteristics of the patients were recorded for 4 months; 501 of the patients recruited, completed this study. Mean age of the patients was $50.9( \pm 16.2)$ years. $48.7 \%$ of patients were female. Mean of the hemoglobin value in all of the 4 centers was $9.29( \pm 1.43)$ $\mathrm{g} / \mathrm{dL}$ at beginning of the study and reached 10.96 $( \pm 2.23) \mathrm{g} / \mathrm{dL}$ after 4 months and showed significant increase overall $(\mathrm{P}<0.001)$. PDpoetin dose was stable at $50-100 \mathrm{U} / \mathrm{kg}$ thrice weekly. Hemorheologic disturbancesand changes in blood electrolytes was not observed. No case of immunological reactions to PDpoetin was observed. Our study, therefore, showed that PDpoetin has significantly raised the level of hemoglobin in the hemodialysis patients (about $1.7 \pm 0.6 \mathrm{~g} / \mathrm{dL}$ ). Anemia were successfully corrected in $49 \%$ of patients under study. Use of this biosimilar was shown to be safe and effective for the maintenance of hemoglobin in patients on maintenance hemodialysis.

\section{Introduction}

Anemia is one of the adverse outcomes in some conditions including End-Stage Renal Disease (ESRD). ${ }^{1}$ There are many different causes for anemia in patients on maintenance hemodialysis, among which lack of folate and B12 vitamin, gastrointestinal bleeding, iron deficiency, serious inflammations and erythropoietin deficiency are of profound importance. ${ }^{2,3}$ When renal function is significantly impaired or if there is no other possible cause for anemia other than chronic kidney disease, erythropoietin deficiency should be considered as underlying cause of anemia. In such cases treatment with erythropoiesis-stimulating agents (ESAs) should be considered. If remain untreated, anemia can drastically impair the patient's quality of life and lead to cardiac complications. ${ }^{4-8}$ Some of associated cardiovascular complications due to anemia, such as left ventricular hypertrophy and fibrosis, may be irreversible. ${ }^{9}$ Therefore, prompt intervention to correct hemoglobin level should be considered. ESAs such as erythropoietin are amongst the most widely used agents in correcting renal anemia.,10-15 The role of recombinant human erythropoietin alpha, as an ESA, in the correction and maintenance of hemoglobin values in patients with ESRD, ${ }^{16}$ cancer associated anemia with low levels of endogenous erythropoietin, ${ }^{17}$ and HIV positive patients under cytotoxic treatment, has been widely studied for correcting anemia in ESRD patients. ${ }^{18}$ In patients on maintenance hemodialysis hemoglobin levels must be maintained more than 11 $\mathrm{g} / \mathrm{dL}$ and hematocrit values must be maintained above 33\% according to the European Best Practice Guidelines (EBPG) for the management of anemia in patients with chronic kidney disease, ${ }^{19}$ or in the range of $11-12 \mathrm{~g} / \mathrm{dL}$ according to National Kidney FoundationKidney Disease Outcome Quality Initiative guidelines (NKF-KDOQI). ${ }^{20}$

PDpoetin is a brand of recombinant human erythropoietin alpha produced in Iran by Pooyesh Darou pharmaceuticals. ${ }^{21}$ This drug has successfully passed clinical trial phases IIII; ${ }^{21,22}$ it has been approved by Food and Drug Department of Ministry of Health and Medical
Correspondence: Ahmad Ahmadzadeh, Health Research Institute, Research Center of Thalassemia and Hemoglobinopathy, Ahvazjundishapur Univeristy of Medical Sciences, Golestan Avenue, Ahvaz, Iran. Tel.: +98.611.333.9092 - Fax: +98.611.333.5200. E-mail: ahmad.ahmadzadeh@gmail.com

Key words: kidney failure, chronic/complications, anemia/drug therapy, epoetin alfa, recombinant proteins, renal dialysis.

Contributions: the authors contributed equally.

Conflict of interests: the authors declare no potential conflict of interests.

Received for publication: 24 November 2013.

Revision received: 5 July 2014 .

Accepted for publication: 1 August 2014.

This work is licensed under a Creative Commons Attribution NonCommercial 3.0 License (CC BYNC 3.0).

(C) Copyright A.N. Javidan et al., 2014 Licensee PAGEPress, Italy

Hematology Reports 2014; 6:5195

doi:10.4081/hr.2014.5195

Education of Iran. In a controlled trial on its immunogenicity and eliciting anti-rHuEPO antibody, it has been shown that while administered subcutaneously, there is no significant difference between the immunogenicity levels of PDpoetin and Eprex (Janssen, Australia), another well-known and widely used brand of rHuEPO..$^{23}$ The aim of this study is to scrutinize effectiveness and possible side effects of PDpoetin in a post marketing surveillance study.

\section{Materials and Methods}

\section{Study design}

In the current multicenter, open-label, uncontrolled clinical trial 501 patients receiving PDpoetin in daily practice from different centers around Iran - namely Qom, Sari, Tehran, and Mashhad - were enrolled from the February 2011 since the July, 2011. Each patient received 50-100 IU/kg of PDpoetin, 3 times weekly subcutaneously. If a patient did not respond to initial dose within 4 weeks, doses doubled for each administration. When the ferritin levels was $<100 \mathrm{ng} / \mathrm{mL}$ or the TSAT was $<20 \%, 100 \mathrm{mg}$ of iron over each of the next 10 hemodialysis sessions and then every 2 weeks thereafter was administered intravenously. When subsequent iron parameters remained below these values, a repeat loading of $100 \mathrm{mg}$ after the next 5 hemodialysis sessions was given. 


\section{Recombinant human erythropoietin and other medications}

The rHuEPO provided as PDpoetin by Pouyesh Darou Pharmaceuticals, Islamic republic of Iran produced in the Chinese hamster ovary (CHO) cells. The rHuEPO preparation was formulated in sterile buffered saline solution containing $0.25 \%$ human serum albumin. Intravenous iron was given as Venofer (Aspen Pharmacare, Australia).

\section{Inclusion criteria and exclusion criteria}

Patients on maintenance hemodialysis at least 3 months, $\mathrm{Hct}<30 \%$ or $\mathrm{Hgb}<11 \mathrm{~g} / \mathrm{dL}$, without any serious inflammatory problems $(\mathrm{CRP}<30 \mathrm{mg} / \mathrm{L})$ and serum ferritin $\geq 100$ $\mathrm{ng} / \mathrm{mL}$ or TSAT $\geq 20 \%$ were included in this study. Patients with $\mathrm{BP} \geq 180 / 110$, Hct $\geq 30 \%$ or $\mathrm{Hb}$ level $\geq 11 \mathrm{~g} / \mathrm{dL}$, malignancies, cerebrovascular accident (CVA) and symptomatic Ischemic Heart Disease (IHD) were excluded from this study. Patients were excluded from the study after enrollment and during the study if they had seizures, receive renal transplantation or blood transfusion, changed the modality of dialysis, established systemic or vascular access infection, vascular access thrombosis, CVA, or uncontrolled hypertension and died.

\section{Ethical considerations}

All patients signed informed consent form to take part in this study. Helsinki Declaration criteria and International Ethical Guidelines for Biomedical Research involving Human Subjects were respected. ${ }^{24}$

\section{Data collection}

Data about clinical trial were gathered by directly examining patients and recording the changes in questionnaire by examining physician. Demographic information including age and gender, and common clinical manifestations and patient's profile such as blood pressure (BP), past medical history including ischemic heart disease, CVA, malignancies, hypertension, and blood chemistry parameters consisting of C-reactive protein (CRP, qualitative method), monthly iron parameters including ferritin, serum iron, transferrin saturation (TSAT), basal and weekly hematocrit-hemoglobin (Hct-Hgb) measurements following subcutaneous PDpoetin administration were recorded carefully. Serum samples were collected from poor responders to test for anti-erythropoietin antibodies.

\section{Statistical analysis}

The results of the quantitative variables are expressed as mean values \pm standard deviation (SD) and those of qualitative variables as proportions. Statistical analysis was carried out by SPSS software (version 16, IBM Corporation, New York, USA). The effect of PDpoetin on variables was modeled using linear mixed model analysis. $\mathrm{P}<0.05$ was assumed to be significant.

\section{Results}

\section{Demographic information}

Among those recruited for current study 501 patients completed the study and were included in the analysis of data. 20 patients were lost to follow up due to the following causes: 8 patients were excluded because of at least one of the following causes like hypertension, infection and deep vein thrombosis, 7 patients died of unrelated causes, and 5 patients changed their location. The mean age of participants included in data analysis in all centers was $50.9 \pm 16.2$ years. $48.7 \%$ of patients were female. Underlying causes of CKD in our study population were dominated by hypertension by $30.5 \%$ of all cases, followed by diabetes (26.4\%). The overall cause of renal insufficiency in our study population is depicted in Figure 1.

\section{Dose of recombinant human erythropoietin}

rHuEPO dose titration was done according to previous studies. ${ }^{21,22}$ Briefly, patients received $50 \mathrm{U}$ of $\mathrm{rHuEPO}$ per $\mathrm{kg}$ bodyweight per session at the beginning. The dosage was then titrated according to the response, increasing the dose by $50 \%$ when the increase in Hct was $<2 \%$ over a 2 to 4 -week period, and decreasing the dose by $25 \%$ when the increase in Hct was $>8 \%$ over a period of 4 weeks.

\section{Hemoglobin and hematocrit changes}

Our study showed about $1.7 \pm 0.6 \mathrm{~g} / \mathrm{dL}$ of hemoglobin increase in patients after 4 months of treatment with PDpoetin. The mean hemoglobin level in our study was $9.29( \pm 1.43)$ at the beginning of study and reached 10.9 $( \pm 2.23)$ at the end of the study $(\mathrm{P}<0.001)$ (Figure 2). Mean hematocrit percent values raised from $29.31( \pm 4.56)$ at the beginning of study to $32.05( \pm 6.19)$ after 4 months of PDpoetin administration (Figure 3; Table 1). In $49 \%$ of our patients, anemia was corrected according to the EBPG for the management of anemia in patients with chronic renal failure or NKF-KDOQI and reached more than $11 \mathrm{gr} / \mathrm{dL}$ which is the target level of hemoglobin in the current study. ${ }^{19,25-28}$ Iron metabolism was maintained at acceptable level (Table 2).

\section{Hemorheologic disturbances}

In the current study no blood electrolyte change attributable to use of PDpoetin was observed (Table 3). High blood pressure was observed in $0.6 \%$ of patients, while $5.6 \%$ of patients showed mild to moderate increases in their blood pressure. Overall less than 1\% of our patients showed hemorheologic disturbances in mild to severe levels.

\section{Safety}

Other complications including vertigo,

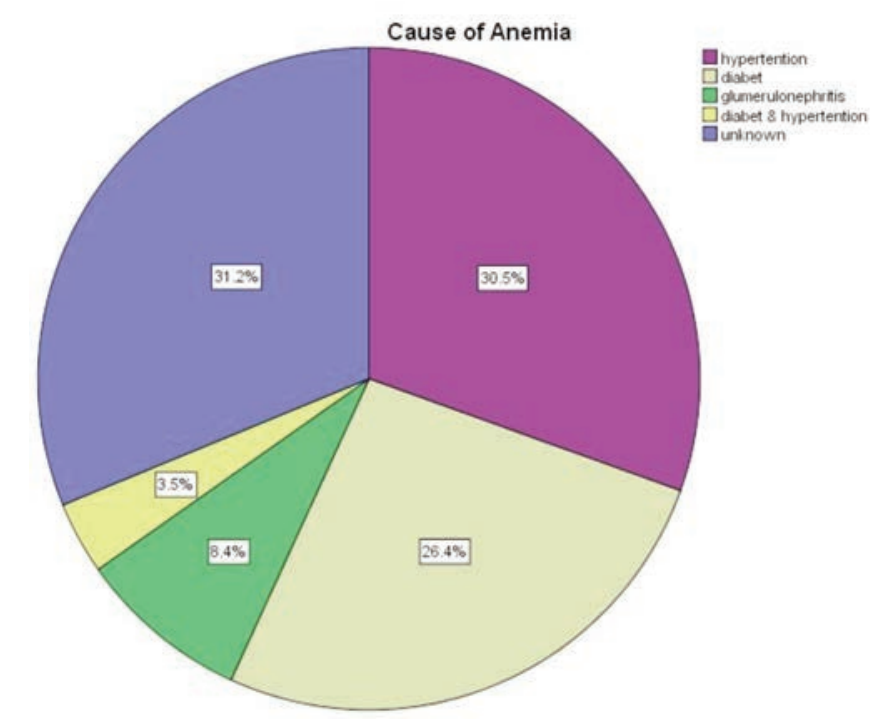

Figure 1. The underlying cause of chronic kidney disease in our study population. Hypertension is the first known underlying cause of renal failure $(30.5 \%)$ in patients in the current study, followed by diabetes (26.4\%), and glomerulonephritis $(8.4 \%)$. About $3.5 \%$ of our patients with end-stage renal disease were suffering from both diabetes and hypertension, while causes of renal failure in $31.2 \%$ of our patients were unknown. 


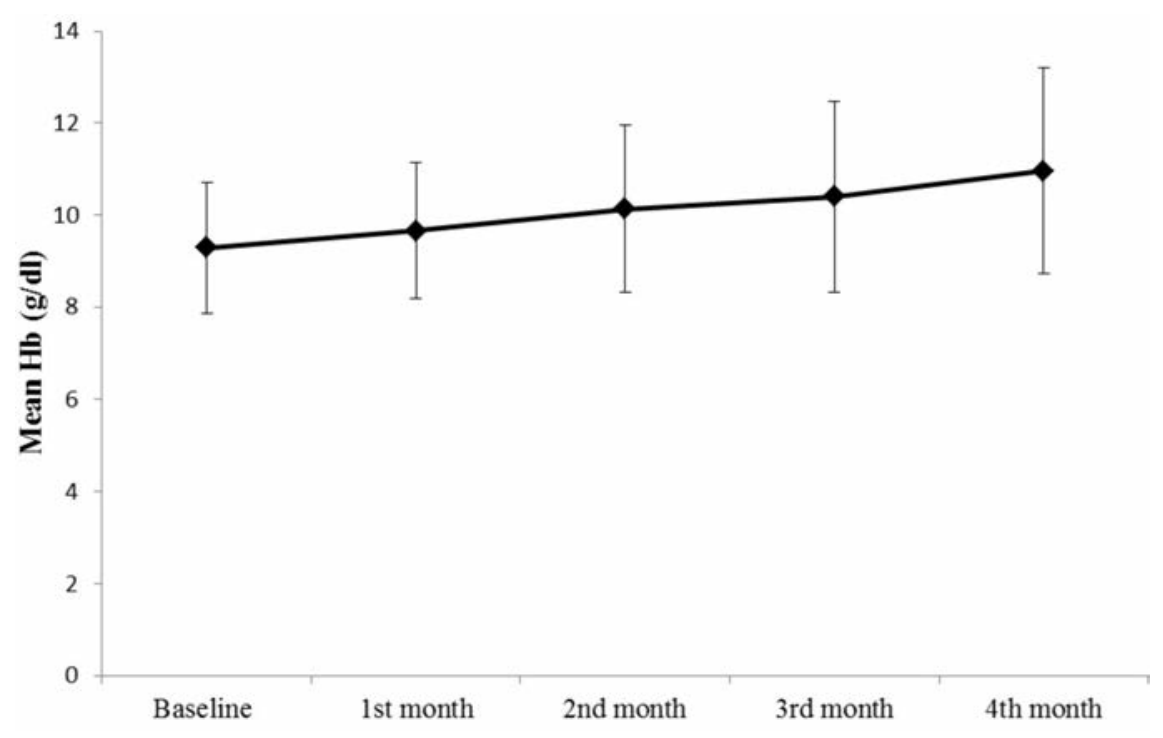

Figure 2. Hemoglobin changes $(\mathrm{g} / \mathrm{dL})$ after beginning of treatment with PDpoetin. HBO, $\mathrm{HB1}, \mathrm{HB} 2, \mathrm{HB} 3$ and $\mathrm{HB} 4$ show respectively mean hemoglobin values at the $0,1,2,3$, and 4 months from beginning of the study.

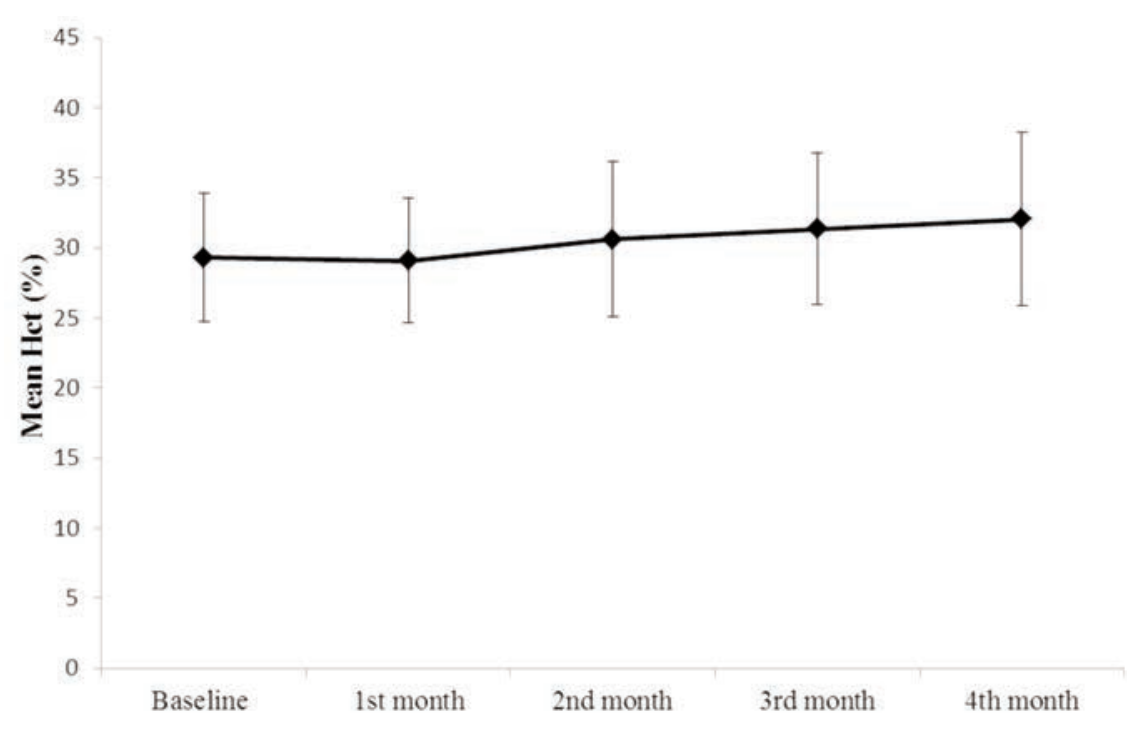

Figure 3. Hematocrit changes after beginning of treatment with PDpoetin. Hct0, Hct1, Hct 2, Hct 3 and Hct 4 show respectively mean hematocrit percent values at the $0,1,2,3$, and 4 months from beginning of the study. lethargy, fever, headache, myalgia, and fatigue were observed with low incidence rate. Totally $97.8 \%$ of patients did not show any of the aforementioned symptoms, $2 \%$ showed mild to moderate adverse symptoms, and $0.2 \%$ of patients showed severe forms of these adverse reactions. Severe pain or other reactions like bruising or inflammation on the site of administration (injection) observed in $0.8 \%$ of patients.

Anti-epoetin immunological reaction resulting in Pure Red Cell Aplasia (PRCA) was not observed in the patients included in this study after subcutaneous (s.c.) administration of PDpoetin. Testing for anti-erythropoietin antibodies in poor responders showed no case of raising antibodies against PDpoetin. Most of the patients had improper dietary habits and many of the cases of treatment failure could be attributed to these inappropriate dietary habits.

\section{Discussion}

Taking into account that this study is an uncontrolled and multicenter trial in a country with its especial culture, and many socio-economical factors associated with treatment, access to treatment, dietary habits, patient follow-up and adherence to therapy must be considered in the interpretation of the data. According to the EBPG for the management of anemia in patients with chronic renal failure or NFK-D0QI our results supported the efficacy of PDpoetin in the treatment of anemia in patients on maintenance hemodialysis. ${ }^{19,20}$ During four months of treatment about half of the patients reached the target level of $11 \mathrm{~g} / \mathrm{dL}$ of hemoglobin. However, the evidence from current study is not enough to compare the efficacy of the PDpoetin to other brands, whereas many factors such as dietary habbits and hemodialysis adequacy may affect the results..$^{29-31}$ These factors have been studied in comparative studies of PDpoetin with Eprex and the studies showed similar efficacy of these two brands in hemoglobin maintenance in hemodialysis patients..$^{21,22}$

Table 1. Hematological parameters presented as mean ( \pm standard deviaton), $\mathrm{n}=501$.

\begin{tabular}{|c|c|c|c|c|c|c|}
\hline Parameter & Baseline & Month 1 & Month 2 & Month 3 & Month 4 & $\mathbf{P}$ \\
\hline $\mathrm{Hb}, \mathrm{g} / \mathrm{dL}$ & $9.29( \pm 1.43)$ & $9.66( \pm 1.48)$ & $10.13( \pm 1.82)$ & $10.4( \pm 2.07)$ & $10.96( \pm 2.23)$ & $<0.001$ \\
\hline Hct, $\%$ & $29.31( \pm 4.56)$ & $29.09( \pm 4.43)$ & $30.61( \pm 5.55)$ & $31.35( \pm 5.38)$ & $32.05( \pm 6.19)$ & $<0.001$ \\
\hline Reticulocytes, \% & $1.29( \pm 0.5)$ & $2.86( \pm 1.1)$ & $1.67( \pm 92)$ & $1.36( \pm 1.13)$ & $1.22( \pm 0.88)$ & 0.014 \\
\hline WBCs $\times 10^{3} / \mathrm{mm}^{3}$ & $7.55( \pm 5.9)$ & $6.5( \pm 5.96)$ & $6.7( \pm 5.64)$ & $6.6( \pm 5.46)$ & $6.14( \pm 2.22)$ & 0.58 \\
\hline
\end{tabular}

Hb, hemoglobin; Hct, hematocrit; WBCs, white blood cells. 
Table 2. Iron metabolism factors presented as mean ( \pm standard deviaton), $\mathbf{n}=501$.

\begin{tabular}{lccccc} 
Parameters & Month 0 & Month 1 & Month 2 & Month 3 & Month 4 \\
S. ferritin $\mu \mathrm{g} / \mathrm{dL}$ & $557.45( \pm 379.75)$ & $643.39( \pm 650.95)$ & $513.34( \pm 423.1)$ & $648.54( \pm 615.49)$ & $658.6( \pm 426.51)$ \\
S. iron $\mu \mathrm{g} / \mathrm{dL}$ & $161.2( \pm 62.16)$ & $163.5( \pm 53.01)$ & $180.7( \pm 43.49)$ & $174.4( \pm 102.13)$ & $176.3( \pm 152.02)$ \\
\hline TIBC $\mu \mathrm{g} / \mathrm{dL}$ & $272.66( \pm 105.7)$ & $371.4( \pm 53.2)$ & $319.6( \pm 103.5)$ & $294.2( \pm 144.2)$ & $249.8( \pm 80.3)$ \\
TSAT \% & $47.53( \pm 60.15)$ & $22( \pm 13.52)$ & $16.61( \pm 10.81)$ & $46.83( \pm 42.97)$ & - \\
\hline
\end{tabular}

TIBC, total iron-binding capacity; TSAT, transferrin saturation by iron.

Table 3. Laboratory safety parameters presented as mean ( \pm standard deviaton), $\mathbf{n}=501$.

\begin{tabular}{lcccccc} 
Parameter* & Baseline & Month 1 & Month 2 & Month 3 & Month 4 \\
S. creatinine, mg/dL & & $7.69( \pm 2.53)$ & $8.2( \pm 3.07)$ & $8.23( \pm 3.74)$ & $9.24( \pm 3.45)$ & 0.322 \\
$\mathrm{~K}+\mathrm{mmol} / \mathrm{L}$ & $5.3( \pm 3.09)$ & $5.28( \pm 0.96)$ & $5.26( \pm 1.3)$ & $5.38( \pm 1.00)$ & $5.47( \pm 0.96)$ & 0.254 \\
\hline $\mathrm{Na}+\mathrm{mmol} / \mathrm{L}$ & $138.31( \pm 4.31)$ & $139.49( \pm 6.75)$ & $138.5( \pm 7.84)$ & $138.47( \pm 4.81)$ & $138.75( \pm 7.56)$ & 0.431 \\
$\mathrm{Ca}+\mathrm{mmol} / \mathrm{L}$ & $8.92( \pm 1.05)$ & $8.83( \pm 0.997)$ & $8.68( \pm 1.39)$ & $8.98( \pm 1.41)$ & $8.97( \pm 1.54)$ & 0.468 \\
\hline BUN* & $113.17( \pm 54.17)$ & $111.12( \pm 54.76)$ & $107.41( \pm 51.87)$ & $110.08( \pm 52.64)$ & $119.38( \pm 52.81)$ & 0.379 \\
\hline *Parameters as measured before each dialysis session. Bun, blood urea nitrogen. & & &
\end{tabular}

Results of the current study are consistent with previous observations regarding immunogenicity of PDpoetin after s.c. administration. ${ }^{23}$ Administration of PDpoetin is via s.c. route, while the recommended route of administration for ESAs in patients on dialysis is through intravenous (i.v.) route. S.c. administration is only recommended in patients not on dialysis because of lack of readily available i.v. access. Efficacy of PDpoetin in ESRD patients on maintenance hemodialysis has been proven in controlled trials. Data from current study is consistent with results from previous studies. ${ }^{20,21}$ In terms of safety, our study proved the safety of PDpoetin for clinical use in ESRD patients on maintenance hemodialysis.

\section{Conclusions}

Our study confirmed the efficacy of PDpoetin in treatment of anemia in patients on maintenance hemodialysis. Also, our study demonstrated that PDpoetin use is not associated with any significant side effects attributable to the use of this agent.

\section{References}

1. Locatelli F, Pisoni RL, Combe C, et al. Anaemia in haemodialysis patients of five European countries: association with morbidity and mortality in the Dialysis Outcomes and Practice Patterns Study (D0PPS). Nephrol Dial Transplant 2004;19:121-32.

2. Richards N, Ayala JA, Cesare S, et al.
Assessment of quality guidelines implementation using a continuous quality improvement programme. Blood Purif 2007;25:221-8.

3. Valderrabano F. Anaemia management in chronic kidney disease patients: an overview of current clinical practice. Nephrol Dial Transplant 2002;17:13-8.

4. Barany P, Muller HJ. Maintaining control over haemoglobin levels: optimizing the management of anaemia in chronic kidney disease. Nephrol Dial Transplant 2007;22:iv10-8.

5. Chavers BM, Herzog CA. The spectrum of cardiovascular disease in children with predialysis chronic kidney disease. Adv Chronic Kidney Dis 2004;11:319-27.

6. Eckardt KU. Managing a fateful alliance: anaemia and cardiovascular outcomes. Nephrol Dial Transplant 2005;20:vi16-20.

7. Eknoyan G. The importance of early treatment of the anaemia of chronic kidney disease. Nephrol Dial Transplant 2001;16:459.

8. Jaradat MI, Molitoris BA. Cardiovascular disease in patients with chronic kidney disease. Semin Nephrol 2002;22:459-73.

9. Parfrey P. Anaemia in chronic renal disease: lessons learned since Seville 1994. Nephrol Dial Transplant 2001;16:41-5.

10. Cody J, Daly C, Campbell M, et al. Frequency of administration of recombinant human erythropoietin for anaemia of end-stage renal disease in dialysis patients. Cochrane Database Syst Rev 2002:CD003895.

11. Cody J, Daly C, Campbell M, et al. Recombinant human erythropoietin for chronic renal failure anaemia in pre-dialysis patients. Cochrane Database Syst Rev 2005:CD003266.
12. Coronel F, Herrero JA, Montenegro J, et al. Erythropoietin requirements: a comparative multicenter study between peritoneal dialysis and hemodialysis. J Nephrol 2003;16:697-702.

13. Jacobs C, Frei D, Perkins AC. Results of the European Survey on Anaemia Management 2003 (ESAM 2003): current status of anaemia management in dialysis patients, factors affecting epoetin dosage and changes in anaemia management over the last 5 years. Nephrol Dial Transplant 2005;20:iii3-24.

14. Ritz E, Eisenhardt A. Early epoetin treatment in patients with renal insufficiency. Nephrol Dial Transplant 2000;15:40-4.

15. Soffritti S, Russo G, Cantelli S, et al. Maintaining over time clinical performance targets on anaemia correction in unselected population on chronic dialysis at 20 Italian centres. Data from a retrospective study for a clinical audit. BMC Nephrol 2009;10:33.

16. Pisoni RL, Bragg-Gresham JL, Young EW, et al. Anemia management and outcomes from 12 countries in the Dialysis Outcomes and Practice Patterns Study (DOPPS). Am J Kidney Dis 2004;44:94111.

17. Bokemeyer C, Aapro MS, Courdi A, et al. EORTC guidelines for the use of erythropoietic proteins in anaemic patients with cancer: 2006 update. Eur J Cancer 2007; 43:258-70.

18. Grossman HA, Goon B, Bowers P, Leitz G. Once-weekly epoetin alfa dosing is as effective as three times-weekly dosing in increasing hemoglobin levels and is associated with improved quality of life in anemic HIV-infected patients. J Acquir Immune Defic Syndr 2003;34:368-78. 
19. Locatelli F, Aljama P, Barany P, et al. Revised European best practice guidelines for the management of anaemia in patients with chronic renal failure. Nephrol Dial Transplant 2004;19:ii1-47.

20. KDOQI, National Kidney Foundation. Clinical Practice guideline and clinical practice recommendations for anemia in chronic kidney disease: 2007 update of hemoglobin target. Am J Kidney Dis 2007;50:471-530.

21. Argani H, Ossareh S, Tabiban S, et al. PDpoietin in comparison with eprex in treatment of anemic patients on hemodialysis. Iran J Kidney Dis 2009;3:145-50.

22. Afshar R, Sanavi S, Kebryaeezadeh A, et al. Hemoglobin and hematocrit rise in endstage renal disease (ESRD) with PDpoetin: results of a phase III, multicenter clinical trial. Iran J Pathol 2008;3:15760.

23. Afshar R, Sanavi S, Naiebpour M, Davati A.
PDpoetin immunogenicity compared with Eprex, in patients undergoing maintenance hemodialysis. J Pharm Res 2009;2:250-3.

24. Puri KS, Suresh KR, Gogtay NJ, Thatte UM. Declaration of Helsinki, 2008: implications for stakeholders in research. J Postgrad Med 2009;55:131-4.

25. KDOQI, National Kidney Foundation. Clinical practice guidelines and clinical practice recommendations for anemia in chronic kidney disease in adults. II. Am J Kidney Dis 2006;47:S16-85.

26. Krantz SB. Review of patients' responses to epoetin alfa therapy. Pharmacotherapy 1990;10:15S-21S.

27. Mohini R. Clinical efficacy of recombinant human erythropoietin in hemodialysis patients. Semin Nephrol 1989;9:16-21.

28. Abbas EE, Afioni N, Al Wakeel J, et al. The new rHuEPO alpha (epotin) in the management of anemia of end-stage renal dis- ease in patients on maintenance hemodialysis. Transplant Proc 2004;36: 1805-11.

29. Ifudu 0, Feldman J, Friedman EA. The intensity of hemodialysis and the response to erythropoietin in patients with endstage renal disease. New Engl J Med 1996;334:420-5.

30. Sathiyanarayanan S, Ch SS, Pawar SM, Prabhakar E. Effect of oral l-carnitine supplementation on serum lipid profile and creactive protein levels in maintenance haemodialysis patients. Curr Res Microbiol Biotechnol 2014;2:364-6.

31. Wu IW, Hsu KH, Sun CY, et al. Oral adsorbent AST-120 potentiates the effect of erythropoietin-stimulating agents on stage 5 chronic kidney disease patients: a randomized crossover study. Nephrol Dial Transplant 2014 Apr 8. [Epub ahead of print]. 